\title{
KARAKTER TOKOH KI BAGUS RANGIN PAHLAWAN PERANG KEDONDONG DI CIREBON
}

\author{
Faviantio Farhan ${ }^{1)}$, Winny Gunarti Widya Wardani ${ }^{2)}$, Febrianto Saptodewo ${ }^{3)}$ \\ Program Studi Desain Komunikasi Visual, \\ Fakultas Bahasa dan Seni, Universitas Indraprasta PGRI \\ Jl. Nangka No. 58 C, Tanjung Barat, Jakarta Selatan, 12530, Indonesia
}

faviantio11@gmail.com

\begin{abstract}
Abstrak
Ki Bagus Rangin merupakan tokoh sentral di Cirebon pemimpin perlawanan rakyat Cirebon untuk melakukan perlawanan terhadap penjajah belanda. Setiap perjuangannya Ki Bagus Rangin selalu menyempatkan diri melakukan dakwah, bertujuan agar rakyat mendapat dukungan semangat nasionalisme, serta mendapatkan unsur moral agama. Ki Bagus Rangin merupakan pemimpin berkharismatik yang mencintai rakyatnya, mampu menggetarkan hati masyarakat dari sikap positif yang diajarkannya. Sikap positif dari Ki Bagus Rangin bisa kita ambil hikmahnya dan mencotohkan di kehidupan sehari-hari. Metode yang digunakan dalam pengumpulan data bersifat kualitatif, yaitu dengan cara mencari data literatur, wawancara, observasi. Studi ini merancang tokoh Ki Bagus Rangin pahlawan Perang Kedondong untuk dijadikan karakter dalam motion comic. Perancangan berguna untuk mengenalkan tokoh sejarah kepada remaja. Konsep gambar manga dipilih karena pada dasarnya, remaja di Indonesia senang membaca komik Jepang.
\end{abstract}

Kata Kunci: Ki Bagus Rangin, Perang, Kedondong, Cirebon, pahlawan, Motion Comic

\begin{abstract}
Ki Bagus Rangin is a central figure in Cirebon for Cirebon people to fight against the Dutch invaders. Every struggle of Ki Bagus Rangin always took the time to do da'wah, orientation so that people got the spirit of nationalism, and made no religious morality. Ki Bagus Rangin is a charismatic leader who loves his people, is able to thrill the hearts of the people from the positive attitude he teaches. We can take a positive attitude from Ki Bagus Rangin and make it memorable in our daily lives. The method used in data data is qualitative, that is by looking for literature data, interviews, interviews. This study designed the character Ki Bagus Rangin hero of the Kedondong war to be used as a character in motion comic. Design is useful for introducing historical figures to teenager. The concept of manga is used because basically, teenagers in Indonesia love to read Japanese comics.
\end{abstract}

Keywords: Ki Bagus Rangin, War, Kedondong, Cirebon, Hero, Motion Comic

Correspondence author: Faviantio Farhan, faviantio11@gmail.com, Jakarta Selatan, and Indonesia

This work is licensed under a $C C-B Y-N C$ 


\section{PENDAHULUAN}

Pahlawan kemerdekaan adalah sebutan bagi orang yang telah berjuang memerdekakan Indonesia. Pahlawan kemerdekaan tidak segan-segan untuk mengorbankan jiwa, raganya, serta mempertahankan martabat negara tanpa ada sedikit rasa mengharapkan imbalan dari Pemerintahan. Perjuangan dan keberanian pahlawan kemerdekaan merupakan sebuah ketulusan langsung dari hati. Perjuangan pahlawan itulah yang membuat saat ini bisa merasakan kebebasan dari bangsa penjajah dan tidak sedikit pahlawan yang gugur dalam medan peperangan hanya demi Negara Indonesia, prestasi mereka sudah seharusnya mendapatkan apresiasi dan dibanggakan hingga zaman sekarang.

Ki Bagus Rangin adalah salah satu pemimpin dari gerakan pemberontakan rakyat yang sangat berpengaruh. Beliau dalam perjuangannya selalu melakukan pidato dan ceramah untuk menggetarkan dan menggerakan hati masyarakat. Pasukan Bagus Rangin terdiri dari para masyarakat biasa yang tidak mempunyai keberanian dalam berperang, namun pemimpin yang karismatik ini mampu menggerakan masyarakat sehingga mempunyai api semangat untuk melawan penjajah. Walaupun mereka tahu akan persenjataan dan perlengkapan penjajah yang lengkap, tidak sedikit pun menggetarkan nyali pasukan Bagus Rangin (Dasuki, 1977: 181).

Sifat Ki Bagus Rangin digambarkan sebagai pemimpin yang gagah berani dan siap menyatakan perang demi kedaulatan negara dan rakyat Indonesia dari rampasan penjajah dengan didukung oleh pengikutnya yang banyak. Semangat perjuangannya telah memberikan inspirasi terhadap para tokoh pejuang di Cirebon di kemudian hari. Pengaruh Bagus Rangin di kalangan pengikutnya sangat besar. Keistimewaan Ki Bagus Rangin adalah ketika sebelum berperang melawan Belanda, selalu memberikan dakwah kepada masyarakat, guna menaikkan moral dan nilai agama (Ernaka, 1993: 42).

Peristiwa perang Kedongdong atau Perang Cirebon sendiri pencetusnya adalah Ki Bagus Rangin pada awal abad ke-19 diawali situasi Cirebon yang begitu mencekam bagi orang-orang yang bertempat tinggal di area Keraton, wilayah Cirebon tampak tak berpenghuni, begitu sepi. Mereka semua bergabung dengan para pejuang di bawah pimpinan Bagus Rangin. Tuntutan para pejuang itu adalah memulangkan para tentara Batavia, serta mengembalikan Raja Kanoman, Raja Kabupaten, dan Raja Lahutan ke Cirebon. Akhirnya, Nicolas Engelhard menyetujui tuntutan itu. Dengan begitu, berakhirlah pemberontakan Ki Bagus Rangin (Iryana, 2017: 374).

Berdasarkan pemaparan di atas, sebagai bentuk apresiasi terhadap para pahlawan yang telah gugur dalam memperjuangkan kemerdekaan Indonesia, maka perlunya penyampaian kembali perjuangan para pahlawan tersebut. Hal itu bertujuan sebagai pengingat dan dapat dijadikan tauladan untuk generasi berikutnya.

Salah satu media yang sesuai dengan perkembangan zaman saat ini adalah motion comic. Sebagai langkah awal dalam penelitian ini adalah perancangan tokoh atau karakter Ki Bagus Rangin yang nantinya akan diaplikasikan dana media motion comic. Tujuan penciptaan karakter Ki Bagus Rangin adalah sebagai contoh sosok pemimpin kepada remaja agar bisa dijadikan suri tauladan yang baik bagi remaja di zaman sekarang.

Penelitian ini bertujuan, di antaranya sebagai upaya memperoleh ilmu dan tata cara merancang karakter, sebagai bentuk pengenalan, seberapa besarnya perjuangan tokoh Ki Bagus Rangin dalam melawan bangsa Belanda di tanah Jawa. Hal itu dikarenakan Ki Bagus Rangin merupakan sosok yang cocok untuk dijadikan panutan, terkait nasionalisme dan religiusitas, kepada remaja pada masa sekarang, sekaligus agar sosok Ki Bagus Rangin selalu dikenang dikemudian hari.

\section{METODE PENELITIAN}

Metode penelitian objek Ki Bagus Rangin bersifat Kualitatif. Kegiatan penelitian seperti mencari sumber informasi, serta teknik pengumpulan data, mencari sumber referensi dari beberapa literatur, situs web, wawancara pada narasumber pembuat buku, sejarawan Indramayu, dan observasi yang dilakukan secara langsung ke Keraton Kanoman. Observasi juga dilakukan di kota Cirebon tepatnya Desa Kedondong, Kecamatan Susukan, J1. Ki Bagus Rangin. 
Metode kualitatif menurut Herdiansyah (2012: 18) adalah suatu penelitian yang bertujuan untuk memahami dari suatu kejadian sosial yang terjadi secara alamiah dengan menggunakan proses interaksi komunikasi yang lebih dalam antara peneliti dengan kejadian yang sedang diteliti.

Metode perancangan menggunakan metode perubahan bentuk yang sesaui dengan pendapat Sari (2015: 15) bahwa metode dari perubahan wujud terdiri dari stilasi, distorsi, simplicity transformasi dan disformasi. Lebih khusus, metode yang digunakan dalam perancangan karakter Ki Bagus Rangin menggunakan morfologi bentuk yaitu simplicity karena mengambil segmen remaja. Remaja saat ini menyukai bentuk yang terkesan simple/tidak rumit sehingga mudah dipahami.

\section{HASIL DAN PEMBAHASAN}

Dimulai dalam perlawanan tahun 1806 itu, Bagus Rangin menjadi pimpinan dari pergerakan rakyat daerah. Ki Bagus Rangin dalam kepemimpinannya juga dibantu oleh beberapa pemimpin perlawanan lainnya dalam bertindak yang menyebabkan, bangsa Belanda mengalami kerugian yang sangat besar. Sifat Ki Bagus Rangin yang gagah berani seakan melumpuhkan pergerakan Belanda. Masyarakat Cirebon dan Ki Bagus Rangin melakukan gerakan perlawanan sesuai kedudukannya masing-masing.

Kehebatan Ki Bagus Rangin dalam memimpin, eksistensi jiwa kepemimpinan Ki Bagus Rangin sangat diakui pihak sekutu maupun lawan dan kepemimpinan Ki Bagus Rangin sangat jelas terlihat karena mampu menyatukan penduduk dari berbagai macam wilayah di Cirebon sejumlah 40.000 orang. Walaupun menggunakan senjata tradisional yang seadanya Ki Bagus Rangin tetap teguh melawan pemerintahan Belanda. Jiwa patriotismenya yang seakan lebih baik berjuang sampai akhir hayatnya, dibandingkan harus tunduk dengan pasukan Belanda (Sudirja, 2005: 41).

Strategi-strategi dari Ki Bagus Rangin sangatlah cerdik dan dingin ketika mengambil sebuah keputusan yang membuat Ki Bagus Rangin sangat ditakuti lawan dan dihormati masyarakat Cirebon (Noor, 2013: 10).

Dikatakan pada tahun 1812 Ki Bagus Rangin tertangkap oleh Belanda, namun dalam sumber lokal seperti Babad Mertasinga dan Babad Dermayu disebutkan bahwa Bagus Rangin masih hidup dan turut serta menjadi bagian dalam perlawanan di Kedongdong tahun 1818. Setelah kabar tertangkapnya Bagus Rangin, perlawanan berhenti sementara hingga kemudian muncul kembali pada tahun 1816 sampai 1818 yang dipimpin oleh Bagus Jabin lalu oleh Bagus Serit.

Berita akan tertangkapnya Bagus Rangin ternyata bukan untuk menggetarkan dan melemahkan mental para masyarakat malah sebaliknya, seakan Bagus Rangin adalah pahlawan yang mempunyai aura akan semangat. Patriotismenya yang sangat tinggi menularkan sifatnya untuk para rakyatnya sehingga selalu menjadi api semangat di hati para masyarakat (Rahayu, 2016: 167).

Tokoh Ki Bagus Rangin seakan mencontohkan bahwa, kita harus tetap mempertahankan kedaulatan Indonesia walaupun harus mengorbankan jiwa dan raga kita. Sifat Ki Bagus Rangin yang memotivasi peneliti untuk terus melanjutkan perjuangan Ki Bagus Rangin dengan cara menyampaikan pada generasi muda, bahwa Ki Bagus Rangin rela berkorban dan berani dalam melawan penjajah Belanda.

Di zaman sekarang remaja sangat kecanduan akan media yang berhubungan dengan digital, buku-buku sejarah seakan menjadi hal yang membosankan bagi remaja, faktanya remaja lebih menyukai film tokoh pahlawan luar negeri dan character komik dari Jepang ketimbang membaca buku sejarah tokoh pahlawan, ditambah gadget yang super canggih menambah sifat malas pada remaja untuk membaca buku.

Karakter Ki Bagus Rangin dirancang sebagai pengingat jasa-jasa Ki Bagus Rangin yang berani melawan penjajah Belanda. Segmentasi yang ditujukan untuk remaja umur 15-18 tahun. Menurut Marliani (2016: 225), masa remaja adalah masa pencarian identitas diri yang berarti masa remaja tidak mengalami pemikiran yang bisa melakukan filterisasi, remaja tidak tahu mana yang buruk, mana yang baik, remaja akan melakukan sesuatu hal yang mereka sukai, atau kagumi. Dan remaja sangat mengidolakan sosok panutan, dibandingkan remaja mengidolakan tokoh- 
tokoh yang bersifat negatif, lebih baik remaja dikenalkan tokoh kemerdekaan yang mempunyai sisi positif.

Sejarah bukan sekadar melahirkan kriteria dari peristiwa di masa lalu, tetapi pemahaman masa lampau yang mempunyai berbagai dinamika, mungkin berisi problematika pelajaran bagi manusia berikutnya yang berarti sejarah wajib dikenalkan dan dipelajari oleh remaja.

Studi ini bertujuan menciptakan karakter Ki Bagus Rangin sebagai sosok pahlawan yang bisa dijadikan contoh kepada remaja tentang akhlak, rasa nasionalisme, dan perjuangannya yang rela berkorban demi kedaulatan bangsa Indonesia. Karakter dirancang sebagai dasar perancangan media pembelajaran kepada remaja agar mudah menerima informasi, sesuai minat dan kesukaan remaja. Konsep dasar perancangan berdasarkan dari beberapa element yaitu:

\section{Character Design}

Berdasarkan teori character design dalam Saptodewo (2018: 78) yang berjudul "Perancangan Karakter Bregada Keraton Yogyakarta Sebagai Media Visual Pendukung Photo Booth", character design merupakan suatu bentuk ilustrasi yang menampilkan sebuah gambaran yang hadir dari konsep "manusia" dengan segala ciri fisiknya (sifat, fisik, profesi, bahkan takdir). Character design mempunyai peran dalam mengajak khalayak untuk mengenali sebuah character dan memberikan kesan kepada khalayak yang ditimbulkan dari emosi suatu character design.

\section{Target Remaja}

Remaja merupakan usia yang sangat mengidolakan tokoh, namun problematika tokoh yang diidolakan pada zaman sekarang membuat remaja krisis akan moralitas karena salah dalam mengidolakan tokoh, dan problematika remaja pada zaman sekarang adalah pahlawan fiksi dari luar negeri yang mampu menggeser tokoh pahlawan asli Indonesia.

Remaja cenderung lebih mengagumi tokoh pahlawan luar negeri dibandingkan pahlawan asli Indonesia. Perancangan karakter Ki Bagus Rangin bertujuan sebagai pengenalan dasar sebagian besar dari tokoh pahlawan Indonesia yang tidak akan kalah oleh tokoh fiksi pahlawan luar negeri.

\section{Gaya Visual}

Gaya Visual yang akan digunakan dalam perancangan karakter Ki Bagus Rangin adalah manga dikarenakan sudah familiarnya manga dalam kehidupan remaja zaman sekarang. Di kehidupan sehari-hari, remaja akrab dengan membaca manga sehingga mudahnya menginformasikan motion comic jika gaya visual menggunakan manga kepada remaja.

Gaya visual merupakan salah satu unsur penting dalam perancangan karakter, karena gaya visual merupakan faktor kunci keefektifan informasi yang diberikan dari karakter. Gaya visual tidak bisa dibuat secara asal, melainkan harus didasari oleh segmentasi target khalayak terlebih dahulu. Berikut ini beberapa gaya visual dari berbagai macam komik yang pupuler, pada kalangan remaja di Indonesia:

\section{Komik Amerika}



Gambar 1. Komik Amerika

Sumber: http://www.tamsirstudio.16mb.com, diakses tanggal: 6 November 2018 
Karakteristik dari komik amerika adalah lebih menampilkan sisi muscle atau otot-otot pada setiap karakternya, serta mempunyai banyak garis shading yang terkesan rumit.

\section{Jepang Komik (Manga)}

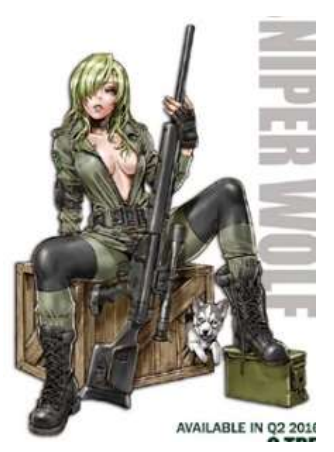

Gambar 2. Komik Manga Jepang

Sumber: http://www.tamsirstudio.16mb.com, diakses tanggal: 6 November 2018

Komik dengan aliran manga saat ini sangat populer, tidak hanya di negeri asalnya, Jepang, tetapi juga hampir di seluruh dunia. Ciri utama dari aliran ini adalah gambar karakternya yang sederhana (mata bulat besar, hidung setitik, dan mulut segaris).

\section{Alernatif karakter}

Alternatif karakter bertujuan sebagai referensi dari beberapa gaya gambar ketika melakukan proses perancangan karakter Ki Bagus Rangin. Yang kemudian akan dipilih sesuai dengan segmentasi.

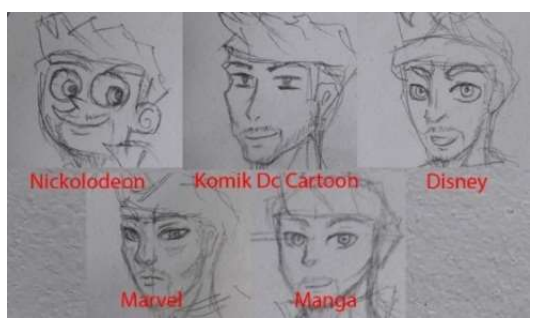

Gambar 3. Beberapa alternatif karakter Ki Bagus Rangin Sumber: Dokumen Pribadi

\section{Deskripsi Karya}

Konsep yang digunakan dalam perancangan media adalah semangat api perjuangan, yang dilakukan oleh tokoh Ki Bagus Rangin. Pada tahun 1802, Belanda tidak berhenti untuk menyiksa masyarakat Indonesia, mulai dari sistem pajak yang dinaikan, pengusiran Sultan Kanoman, sampai penyiksaan demi penyiksaan, dilakukan Belanda pada masa itu. Ki Bagus Rangin adalah salah satu tokoh yang gagah berani, untuk maju sebagai sosok pemimpin pemberontakan terhadap bangsa Belanda.

\section{Perancangan Ki Bagus Rangin}

Peneliti menggunakan referensi dari hasil wawancara dengan Wahyu Iryana (2015) selaku penulis Sejarah Pesantren Babakan Ciwaringin Dan Perang Kedongdong 1802-1919, mengatakan bahwa atribut warna pakaian yang digunakan Ki Bagus Rangin tidak berbeda jauh dengan film Jaka Sembung, sedangkan wajah tetap menggunakan referensi dari patung Ki Bagus 
Rangin. Atribut pakaian yang digunakan Ki Bagus Rangin menunjukan bahwa Ki Bagus Rangin adalah pemimpin yang dapat diandalkan oleh masyarakat Cirebon.

Ki Bagus Rangin mempunyai ciri fisik yaitu, tinggi, mempunyai janggut dan kumis, sedangkan atribut yang digunakan oleh Ki Bagus Rangin sendiri adalah ikat kepala khas Cirebon, baju seperti jubah berwarna cokelat, sabuk kain merah dan celana panjang berwarna cokelat, Ki Bagus Rangin menggunakan senjata seperti keris dan cemeti amal rasuli.

Proses digital menggunakan aplikasi Paint Tool Sai, dari pembuatan line art sampai proses pewarnaan.

\section{Karakter Ki Bagus Rangin}

Mood Board



Gambar 4. Mood Board Ki Bagus Rangin Sumber: Dokumen Pribadi

\section{Sketsa Kasar}



Gambar 5 Sketsa Kasar Ki Bagus Rangin Sumber: Data Pribadi

\section{Digitalisasi Ki Bagus Rangin menggunakan Paint Tool Sai}



Gambar 6. Proses Digital Ki Bagus Rangin Sumber: Dokumen Pribadi 


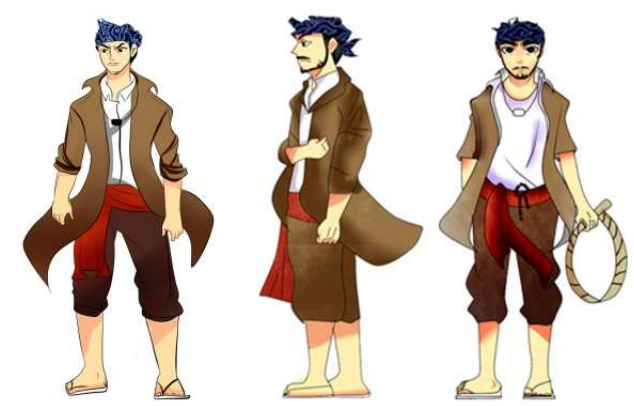

Gambar 7. Final Art Ki Bagus Rangin

Sumber: Dokumen Pribadi

\section{SIMPULAN}

Pentingnya sosok Ki Bagus Rangin sebagai tokoh sejarah dalam perang Kedondong merupakan sebuah sejarah yang tidak bisa dilupakan, baik orang tua terutama remaja. Remaja merupakan usia penting dalam melanjutkan dan menjaga sejarah yang kelak dikemudian hari akan menjadi tanggung jawab mereka, jika tidak diajarkan sejak usia remaja bukan tidak mungkin sejarah bangsa Indonesia akan terkikis oleh zaman.

Keunggulan dalam rancangan karakter Ki Bagus Rangin ini adalah menyampaikan sebuah informasi perjuangan dan sifat Ki Bagus Rangin dari sebuah karakter yang mudah dipahami remaja.

\section{DAFTAR PUSTAKA}

Dasuki, (1977). Sejarah Indramayu, Indramayu: Pemerintah Kabupaten Daerah tingkat 2 Indramayu.

Herdiansyah, (2012). Metodologi penelitian kualitatif. Jakarta: Salemba Humanika.

Iriyana, W. (2015). Baban Kana (Pondok Pesantren Ciwaringin dalam Melacak Perang Kedondong 1802-1919) https://wahyuiryanawayan.blogspot.com/2015/07/baban-kanapondok-pesantren-ciwaringin_1.html

Komik Amerika. (2018).http://www.tamsirstudio.16mb.com

Komik Jepang. (2018). http://www.tamsirstudio.16mb.com

Marliani, (2016). Psikologi perkembangan anak dan remaja. Bandung: CV Pustaka Setia.

Noor, (2013). Dari Rangin ke telepon, Depok: PT Jurnal Sajak Indonesia.

Saptodewo, F. (2018). Perancangan karakter bregada keraton Yogyakarta sebagai media visual pendukung photo booth. Jurnal Desain, 5(02), 74-85.

Sudirja, (2005). Ki Bagus Rangin penggerak perlawanan rakyat menentang penjajahan Belanda. Jakarta: Cv Ricardo Sylado, 2007. Ratu Adil, Solo: Tiga Serangkai. 